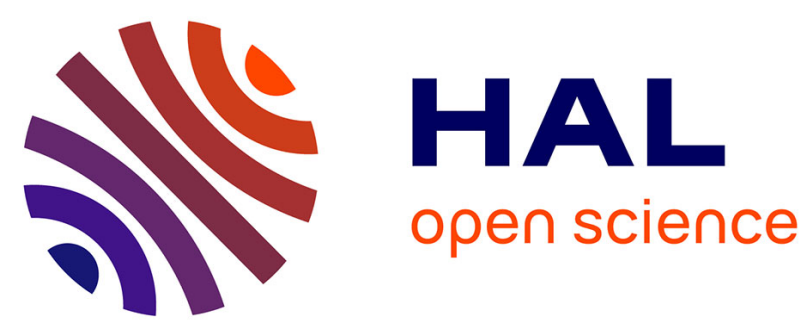

\title{
Association between long-term exposure to air pollution and mortality in France: A 25-year follow-up study
}

Malek Bentayeb, Vérène Wagner, Morgane Stempfelet, Marie Zins, Marcel Goldberg, Mathilde Pascal, Sophie Larrieu, Pascal Beaudeau, Sylvie Cassadou, Daniel Eilstein, et al.

\section{To cite this version:}

Malek Bentayeb, Vérène Wagner, Morgane Stempfelet, Marie Zins, Marcel Goldberg, et al.. Association between long-term exposure to air pollution and mortality in France: A 25-year follow-up study. Environment International, 2015, 85, pp.5-14. 10.1016/j.envint.2015.08.006 . hal-01187145

HAL Id: hal-01187145

https://hal-univ-rennes1.archives-ouvertes.fr/hal-01187145

Submitted on 2 Nov 2015

HAL is a multi-disciplinary open access archive for the deposit and dissemination of scientific research documents, whether they are published or not. The documents may come from teaching and research institutions in France or abroad, or from public or private research centers.
L'archive ouverte pluridisciplinaire HAL, est destinée au dépôt et à la diffusion de documents scientifiques de niveau recherche, publiés ou non, émanant des établissements d'enseignement et de recherche français ou étrangers, des laboratoires publics ou privés. 
Association between long-term exposure to air pollution and mortality in France: a 25year follow-up study.

Malek Bentayeb ${ }^{1}$, Verene Wagner ${ }^{1}$, Morgane Stempfelet ${ }^{1}$, Marie Zins ${ }^{2,3}$, Marcel Goldberg ${ }^{2,3}$, Mathilde Pascal $^{1}$, Sophie Larrieu ${ }^{1}$, Pascal Beaudeau ${ }^{1}$, Sylvie Cassadou${ }^{1}$, Daniel Eilstein ${ }^{1}$, Laurent Filleul $^{1}$, Alain Le Tertre ${ }^{1}$, Sylvia Medina ${ }^{1}$, Laurence Pascal ${ }^{1}$, Helene Prouvost ${ }^{1}$, Philippe Quénel ${ }^{1,4}$, Abdelkrim Zeghnoun ${ }^{1}$, Agnes Lefranc ${ }^{1}$.

${ }^{1}$ French Institute for Public Health Surveillance (InVS), Saint-Maurice, France

${ }^{2}$ Inserm, Population-based Epidemiologic Cohorts Unit, UMS 011, Villejuif, France

${ }^{3}$ Versailles St-Quentin University, UMS 011, F-94807, Villejuif, France

${ }^{4}$ School of Public Health (EHESP/SPC) - IRSET Inserm UMR 1085, Rennes, France

\section{Corresponding author}

\section{Malek Bentayeb}

French Institute for Public Health Surveillance (InVS), 12 rue du Val d'Osne, 94415 SaintMaurice Cedex France

m.bentayeb@invs.sante.fr

$\underline{0033141796970}$

Running head: Long-term exposure to air pollution and mortality 


\section{ABSTRACT}

INTRODUCTION Long-term exposure to air pollution (AP) has been shown to have an impact on mortality in numerous countries, but since 2005 no data exists for France.

OBJECTIVES We analyzed the association between long-term exposure to air pollution and mortality at the individual level in a large French cohort followed from 1989 to 2013.

METHODS The study sample consisted of 20,327 adults working at the French national electricity and gas company EDF-GDF. Annual exposure to $\mathrm{PM}_{10}, \mathrm{PM}_{10-2.5}, \mathrm{PM}_{2.5}, \mathrm{NO}_{2}, \mathrm{O}_{3}$, $\mathrm{SO}_{2}$, and benzene were assessed for the place of residence of participants using a chemistrytransport model and taking residential history into account. Hazard ratios were estimated using a Cox proportional-hazards regression model, adjusted for selected individual and contextual risk factors. Hazard ratios were computed for an interquartile range (IQR) increase in air pollutant concentrations.

RESULTS The cohort recorded 1,967 non-accidental deaths. Long-term exposures to baseline $\mathrm{PM}_{2.5}, \mathrm{PM}_{10-25}, \mathrm{NO}_{2}$ and benzene were associated with an increase in non-accidental mortality (Hazard Ratio, HR=1.09; 95\% CI: 0.99, 1.20 per $5.9 \mu \mathrm{g} / \mathrm{m}^{3}, \mathrm{PM}_{10-25} ; \mathrm{HR}=1.09$;

95\% CI: $1.04,1.15$ per $2.2 \mu \mathrm{g} / \mathrm{m}^{3}, \mathrm{NO}_{2}: \mathrm{HR}=1.14 ; 95 \% \mathrm{CI}: 0.99,1.31$ per $19.3 \mu \mathrm{g} / \mathrm{m}^{3}$ and benzene $: \mathrm{HR}=1.10 ; 95 \% \mathrm{CI}: 1.00,1.22$ per $\left.1.7 \mu \mathrm{g} / \mathrm{m}^{3}\right)$.The strongest association was found for $\mathrm{PM}_{10}: \mathrm{HR}=1.14 ; 95 \%$ CI: 1.05, 1.25 per $7.8 \mu \mathrm{g} / \mathrm{m}^{3} . \mathrm{PM}_{10}, \mathrm{PM}_{10-25}$ and $\mathrm{SO}_{2}$ were associated with non-accidental mortality when using time varying exposure. No significant associations were observed between air pollution and cardiovascular and respiratory mortality.

CONCLUSION Long-term exposure to fine particles, nitrogen dioxide, sulfur dioxide and benzene is associated with an increased risk of non-accidental mortality in France. Our results strengthen existing evidence that outdoor air pollution is a significant environmental risk factor for mortality. Due to the limited sample size and the nature of our study (occupational), further investigations are needed in France with a larger representative population sample. 
Keywords: Air pollution; mortality; cohort study; epidemiology; France.

\section{Introduction}

Several epidemiological studies have shown positive associations between long-term exposure to outdoor air pollution and mortality(Cesaroni et al. 2013; Crouse et al. 2012; Hoek et al. 2013; Lepeule et al. 2012). A recent report by the World Health Organization (WHO) indicated that 3.7 million deaths were attributable to ambient air pollution in 2012. Approximately 200,000 of these deaths occurred in Europe (http://www.who.int/mediacentre/factsheets/fs313/en/). To date, most of the largest cohorts studying the impacts of long-term exposure to air pollution have been carried out in North America and have focused on particles with diameters of 10 micrometers or less $\left(\mathrm{PM}_{10}\right)$, and particles with diameters of 2.5 micrometers or less $\left(\mathrm{PM}_{2.5}\right)$ (Hart et al. 2011; Lepeule et al. 2012; Villeneuve et al. 2013). However, a growing number of studies are being performed in Europe (Beelen et al. 2008; Cesaroni et al. 2013). In France, the only study to assess the long-term effects of air pollutants on mortality was PAARC, carried out in the 1970s on 14,284 participants (Filleul et al. 2005). In PAARC, exposure was characterized using a measured urban background concentration of sulphur dioxide $\left(\mathrm{SO}_{2}\right)$, black smoke, total suspended particles (TSP), nitrogen dioxide $\left(\mathrm{NO}_{2}\right)$ and nitrogen monoxide (NO). The study concluded that these pollutants had a positive impact on non-accidental, cardiovascular and lung cancer mortality. For instance, non-accidental mortality increased by $5 \%(95 \% \mathrm{CI}, 2-8)$ for a $10 \mu \mathrm{g} / \mathrm{m}^{3}$ increase of TSP.

As trends in air pollution levels have decreased markedly between the 1970s and recent years, new studies investigating the long-term effects of air pollution on mortality and morbidity were needed in France. Moreover, advances in air pollution monitoring and air pollution modeling provide improved assessment of exposure. Raw observations without further data spatialized do not allow local conditions, such as traffic-related air pollution or local dispersion patterns, to be taken into account. This could induce misclassification and bias estimations of 
concentration-response functions. Several exposure assessment methods have been developed that can minimize this bias (Zou et al. 2009), such as land-use regression (Beelen et al. 2013) and dispersion modeling (Bentayeb et al. 2010).

Therefore, we conducted a study to analyze the association between long-term exposure to air pollution and mortality by implementing a model which provided an improved estimation of individual exposure. We assessed the long-term effects of atmospheric $\mathrm{PM}_{2.5}, \mathrm{PM}_{10}, \mathrm{O}_{3}, \mathrm{NO}_{2}$, $\mathrm{SO}_{2}$ and benzene in a large French Cohort followed over 25 years. 


\section{Materials and Methods}

\subsection{Study population}

The study used data from the Gazel cohort which have been extensively described elsewhere (Goldberg et al. 2007). Gazel consists of 20,625 participants recruited among the employees of the French national electricity and gas company, Électricité de France-Gaz de France (EDFGDF), between 1989 and 2013. Follow-up was continuous and data was collected on health status, lifestyle, and socioeconomic and occupational factors.

A postal questionnaire was sent to the participants every year, and data were regularly extracted from EDF-GDF personnel medical files and national registers. Approximately $75 \%$ of the questionnaires were returned annually, and fewer than $2 \%$ of the participants were lost to follow-up over 25 years.

Study participants were geographically distributed throughout France. In the present analysis, we assessed 20 years of air pollution exposure between 1989 and 2008 by taking into account participants' residential history using zip codes. Residential history with annual update was available for most individuals. We excluded participants who lived for over a year outside metropolitan France anytime during the 25-year follow-up period. Accordingly, analyses were conducted on 20,327 subjects.

\subsection{Mortality}

Vital status data came from the company and are accurate and exhaustive since the company pays the retirement pensions. Causes of death were recorded by the French national cause-ofdeath registry and coded using the international classification of diseases (ICD) (ninth revision (ICD-9) until 1998, and tenth revision (ICD-10) thereafter)(Pavillon and Maguin 1993). We considered all causes apart from suicides and accidents (ICD-9 codes 001-799 and ICD-10 codes A00-R99), cardiovascular mortality (ICD-9 codes: 390-459; ICD-10 codes: I00-I99), and respiratory mortality (ICD-9 codes 460-519 or ICD-10 codes J00-J98) including lung 
cancer (ICD-9 code 162 or ICD-10 codes C33-C34). Data on cardiovascular and respiratory causes of death were available from 1989 to 2010. Non-accidental mortality data were available until December 31, 2013.

\subsection{Exposure assessment}

Annual concentrations of $\mathrm{PM}_{10}, \mathrm{PM}_{2.5}, \mathrm{NO}_{2}, \mathrm{SO}_{2}$, benzene and summer averages (15 April 15 September) of the daily maximum 8-hour concentrations of $\mathrm{O}_{3}$ were assessed at $2 \mathrm{~km}$ resolution throughout France from 1989 to 2008 using the CHIMERE chemistry-transport model, mesh refinement and data assimilation with geostatistical analyses. The modeling strategy is summarized in Figure 1 and has been previously described (Bentayeb et al. 2014). Briefly, emission data were taken from the European Monitoring and Evaluation Program emission cadastre (EMEP: http://www.emep.int/index.html) which consists of gridded annual national emissions of $\mathrm{PM}_{10}, \mathrm{NH}_{3}, \mathrm{SO}_{2}, \mathrm{NO}_{\mathrm{x}}, \mathrm{CO}$, benzene and non-methane volatile organic compounds (NMVOC) at $50 \mathrm{~km}$ resolution on the European scale. We complemented the database with data from the Interprofessional Technical Centre for Studies on Air Pollution (CITEPA: http://www.citepa.org/en) and European Environment Agency (EEA: http://www.eea.europa.eu). The determinist chemistry-transport model CHIMERE was used to provide an initial calculation at $30 \mathrm{~km}$ resolution at the European scale and on a $10 \mathrm{~km}$ resolution nested domain covering France (Menut et al. 2012). Mesh refinement was then performed to improve the spatial distribution of concentrations at $2 \mathrm{~km}$ resolution. Finally, data assimilation allowed us to enhance the accuracy of pollutant concentration estimations.

Participants were assigned annual air pollutant concentrations based on their five-digit zip code. Changes in residence during the year were taken into account. 


\subsection{Confounders}

The following data were considered as potential individual confounding variables and included at baseline in the analyses:

- age, sex, and occupational level (high grade (managers)/ intermediate grade (technical staff, line managers, and administrative associated professionals)/ lower grade (clerical and manual workers)) were collected from $E D F-G D F$ human resources files;

- marital status (married/cohabiting, divorced/separated or widowed or single), highest level of education (high (high school diploma, university, advanced technical certification), intermediate (lower/middle secondary school, professional certification), or low (primary school)), smoking status (smoker, ex-smoker or non-smoker), alcohol intake (high ( $>4$ glasses of wine or beer per day or daily intake of spirits), medium (3-4 glasses of wine or beer per day), low (1-2 glasses of wine or beer per day), or non-drinker)) and body mass index (BMI; weight $(\mathrm{kg}) /$ height $\left.\left(\mathrm{m}^{2}\right)\right)$ were self-reported.

Moreover, because of the potential regional trends in exposure between northern and southern France, especially with respect to ozone, which their concentration is higher in southern, we adjusted data for the region of residence (north, south) according to the zip code taking into account residential history.

In addition, we used data from the population census of 1999 (from the French National Institute of Statistics and Economic Studies (INSEE)) to develop the following contextual confounders at zip code level for each participant: Townsend deprivation index (unemployment, non-car ownership, non-home ownership, and household overcrowding) (Townsend et al. 1988) , percentage of households not liable for tax, and population density (urban, suburban and rural). Moreover, we considered average temperature and principal road network density (sum of roads lengths divided by zip code surface area) for 1999.

\subsection{Statistical analysis}


Cox proportional hazards models were used to explore the relationships between air pollutant exposure and mortality. The time variable used in the models was the survival time from the date of enrollment. We fitted separate models for each air pollutant and each mortality cause and tested fixed exposure as (1) annual mean exposure at baseline (1989) (2) annual mean exposure one year before death or censure (for each participant we assigned mean concentration of the year preceding death or censure) and time dependent exposures as (3) yearly mean exposure during the follow-up before death or censure (for each participant we assigned annual mean concentration of the year of follow-up) and (4) average cumulative exposure before death or censure (for each participant we calculated average pollutant concentrations from baseline to each year of follow-up, ex : exposure in 2005 was calculated as mean of annual concentrations from 1989 to 2005. In 2006, from 1989 to 2006, etc.).

Analyses were performed between 1989 and 2008 for time lags (2) and (3) above (exposure data were not available after $31^{\text {st }}$ December 2008).

All models were adjusted for individual and contextual confounders in multivariate analyses.

All confounders were included as fixed covariates in the models. Missing data from any confounder were imputed using the Hot Deck method.

Age , BMI and contextual covariates were introduced into the models as natural splines with 3 degrees of freedom to take into account a possible non-linear relation between mortality and confounders. Statistical interactions were assessed by introducing multiplicative interaction terms into the Cox regression models to test for effect modification by individual covariates including age at enrollment, sex, smoking status and occupational level. In addition, we tested a possible effect modification by density of population defined by: rural $=0-32$ inhabitants $/ \mathrm{km}^{2}$, suburban $=33-441$ inhabitants $/ \mathrm{km}^{2}$, urban $=442-41607$ inhabitants $/ \mathrm{km}^{2}$ and length of followup by dividing up the whole period into four equal intervals: 1989-1994, 1995-2000, 2001-2006 and 2007-2013. We tested bi-pollutant models for $\mathrm{PM}_{2.5}, \mathrm{PM}_{10}, \mathrm{PM}_{10-2.5}$ and benzene when the 
estimated correlation between any two pollutants was less than 0.7. Finally, in sensitivity analyses, we assessed the association between yearly mean exposure to air pollution and nonaccidental mortality by adjusting the model on time-varying confounders. To compare with our initial model (model adjusted on baseline confounders), we restricted analyses to observations assessed in the model adjusted on time-varying confounders. To allow comparison across pollutants, hazard ratios (HR) and $95 \%$ confidence intervals (CI) associated with an interquartile (IQR) increase in air pollution exposure were calculated for each mortality cause. All analyses were performed using R software (version 3.0.1).

\section{Results}

\subsection{Participants}

Baseline characteristics of participants and average air pollutant concentrations across levels of confounders were described in Table 1 . The total study population consisted of 20,327 participants. At enrollment, mean age of the participants was 43.7 years, $72.8 \%$ were male, $90.2 \%$ were married or cohabiting and the mean BMI was 24.5 . A minority $(6.8 \%)$ had no formal education or primary school education, and $18.4 \%$ had a low occupational level. A total of $42.9 \%$ reported that they had never smoked and $2.6 \%$ reported they were non-drinkers. Missing values of individual confounders are outlined in Figure 4.

In 2008, residential zip codes indicated that participants were distributed throughout all included French regions, and that $81 \%$ and $19 \%$ of them lived in urban and rural areas, respectively. This fact would suggest good representativeness of exposure throughout France (Figure 2).

During the follow-up period (from 1989 to 2013), 1,967 participants (9.7\%) died from nonaccidental causes, which $165(0.8 \%)$ and $284(1.4 \%)$ died from cardiovascular and respiratory disease, respectively.

\subsection{Air pollution exposure}


The distribution of modeled concentrations of $\mathrm{PM}_{2.5}, \mathrm{PM}_{10}, \mathrm{PM}_{10-2.5}\left(\mathrm{PM}_{10}\right.$ minus $\left.\mathrm{PM}_{2.5}\right), \mathrm{NO}_{2}$, $\mathrm{O}_{3}, \mathrm{SO}_{2}$ and benzene from 1989 to 2008 at the zip code level is shown in Figure 3.

The box plots describe the fifth percentile, first quartile, median, third quartile, ninety-fifth percentile of the distribution. Descriptive statistics of the discrepancy (bias, RMSE and correlation) between modelled and observed data (measurements from fixed monitoring stations) from 1989 to 2008 for $\mathrm{PM}_{10}, \mathrm{PM}_{2.5}, \mathrm{NO}_{2}, \mathrm{O}_{3}, \mathrm{SO}_{2}$, and benzene were previously detailed (Bentayeb et al. 2014).

Table 2 shows descriptive statistics of air pollution concentrations as mean \pm standard deviation (SD), median and IQR, according to time lag exposure. Annual median concentrations of $\mathrm{PM}_{10}$, $\mathrm{PM}_{2.5}, \mathrm{NO}_{2}$ and $\mathrm{O}_{3}$ at individual zip code level decreased from 1989 to 2008 by $27 \%, 29 \%$, $40 \%$ and $16 \%$, respectively. The largest decreases occurred for $\mathrm{SO}_{2}(86 \%)$ and benzene $(85 \%)$. Pollutant levels remained high in some French regions. For example, $\mathrm{PM}_{10}$ and $\mathrm{PM}_{2.5}$ values remained high in Paris, Etang de Berre (South-Eastern region), Rhône Valley, and Lorraine. Likewise, $\mathrm{O}_{3}$ concentrations were still high in South-Eastern France.

As expected, annual concentrations of most of the air pollutants studied were strongly correlated to each other, especially particles. Ozone was inversely correlated to several air pollutants (Table 2). Similar correlations were observed each year during follow-up (1989 to 2008). 


\subsection{Associations between air pollution and mortality}

Associations between long-term exposure to air pollution and mortality after adjustment for multiple covariates in the French Gazel cohort are outlined in Table 3.

Long-term exposures to baseline $\mathrm{PM}_{2.5}, \mathrm{PM}_{10-25}, \mathrm{NO}_{2}$ and benzene were associated with an increase in non-accidental mortality: HR=1.09; $95 \%$ CI: $0.99,1.20$ per $5.9 \mu \mathrm{g} / \mathrm{m} 3, \mathrm{PM}_{10-25}$; HR $=1.09 ; 95 \%$ CI: $1.04,1.15$ per $2.2 \mu \mathrm{g} / \mathrm{m} 3, \mathrm{NO}_{2}: \mathrm{HR}=1.14 ; 95 \%$ CI: $0.99,1.31$ per $19.3 \mu \mathrm{g} / \mathrm{m}^{3}$ and benzene: $\mathrm{HR}=1.10 ; 95 \% \mathrm{CI}: 1.00,1.22$ per $1.7 \mu \mathrm{g} / \mathrm{m}^{3}$. The strongest association was found for $\mathrm{PM}_{10}: \mathrm{HR}=1.14 ; 95 \% \mathrm{CI}: 1.05,1.25$ per $7.8 \mu \mathrm{g} / \mathrm{m}^{3}$. When we considered fixed annual mean exposure one year before the death or censure, IQR increase of $3.3 \mu \mathrm{g} / \mathrm{m}^{3}$ in $\mathrm{PM}_{10-2.5}$ and $5.5 \mu \mathrm{g} / \mathrm{m}^{3}$ in $\mathrm{SO}_{2}$ were borderline significantly associated with non-accidental mortality :HR= 1.04 (95\% CI, 0.98-1.11) and 1.09 (95\% CI, 0.99-1.20), respectively.

Regarding time varying exposure, increasing yearly mean exposure in IQR of $\mathrm{PM}_{10}\left(7.5 \mu \mathrm{g} / \mathrm{m}^{3}\right)$, $\mathrm{PM}_{10-2,5}\left(3.3 \mu \mathrm{g} / \mathrm{m}^{3}\right)$ and $\mathrm{SO}_{2}\left(5.3 \mu \mathrm{g} / \mathrm{m}^{3}\right)$ was significantly associated with increase in nonaccidental mortality $: H R=1.12(95 \%$ CI, 1.00-1.24), $1.06(95 \%$ CI, $1.00-1.12)$ and $1.10(95 \%$ CI, 1.00-1.21), respectively.

Cumulative exposure showed that an IQR rise in levels of $\mathrm{PM}_{10}\left(6.7 \mu \mathrm{g} / \mathrm{m}^{3}\right), \mathrm{PM}_{10-2.5}(2.3$ $\left.\mu \mathrm{g} / \mathrm{m}^{3}\right)$ and $\mathrm{SO}_{2}\left(7.7 \mu \mathrm{g} / \mathrm{m}^{3}\right)$ was associated with increase in non-accidental mortality: $\mathrm{HR}=1.11$ (95\% CI, 1.00-1.23), 1.09 (95\% CI, 1.02-1.16) and 1.13 (95\% CI, 0.99-1.28), respectively. With respect to death from cardiovascular and respiratory causes, no significant association was observed with any of the air pollution indicators considered. However, a trend was observed between an increased IQR for $\mathrm{PM}_{2.5}, \mathrm{PM}_{10}, \mathrm{PM}_{10-2.5}$ and cardiovascular mortality: $\mathrm{HR}=1.12$ (95\% CI, 0.82-1.52), 1.21 (95\% CI, 0.89-1.63) and 1.13 (95\% CI, 0.95-1.33), respectively, and between $\mathrm{PM}_{10}$ and $\mathrm{PM}_{10-2.5}$ and increase of deaths from respiratory causes : HR were 1.06 (95\% CI, 0.83-1.34) and 1.11 (95\% CI, 0.98-1.27), respectively. 
Interactions to test for effect modification by individual covariates and density of population (urban/suburban/rural) were not statistically significant. However, significant interactions were observed between all air pollutants and period of follow-up (1989-1994, 1995-2000, 2001-2006 and 2007-2013) (Table 4).

In the bi-pollutant models, the effects of air pollutants on non-accidental mortality were slightly lower but remained significant compared with uni-pollutant models (Table 5).

In the sensitivity analyses, the association between yearly mean exposure to air pollution and non-accidental mortality taking into account time-varying confounders (compared to model adjusted on baseline confounders) is described in Table 6 .

\section{Discussion}

Our study explored the relationship between long-term exposure to various air pollutants and mortality from non-accidental, cardiovascular and respiratory causes. To our knowledge, this is one of the most comprehensive epidemiological study conducted in a large French cohort. It included over 20,000 adults followed-up from 1989 to 2013, and focused on the association between mortality and time-varying exposure to various air pollutants modeled at $2 \mathrm{~km}$ resolution.

Our findings are based on data from an occupational cohort, while most of the studies analyzed in literature are population-based.

Our results revealed a significant relationship between long-term exposure to PM and nonaccidental mortality. Baseline and time-varying exposure to $\mathrm{PM}_{10}$ and $\mathrm{PM}_{10-2.5}$ were significantly associated with non-accidental mortality. Our findings are in agreement with a study conducted by Hart et al. which showed that an increase of $10 \mu \mathrm{g} / \mathrm{m}^{3}$ in ambient residential $\mathrm{PM}_{10}$ was associated with a $17 \%(95 \% \mathrm{CI}, 9$-27) increase in non-accidental mortality (Hart et al. 2011). With respect to $\mathrm{PM}_{10-2.5}$, our results support previous findings which found a borderline significant association between $\mathrm{PM}_{10-2.5}$ exposure in the previous 12 months and 
non-accidental mortality for a $10-\mu \mathrm{g} / \mathrm{m}^{3}$ unit change with $\mathrm{HR}=1.13(95 \% \mathrm{CI}, 0.98-1.30)$ (Puett et al. 2009). Another recent study showed a borderline significant association between baseline exposure to $\mathrm{PM}_{10-2.5}$ and non-accidental mortality for a $5-\mu \mathrm{g} / \mathrm{m}^{3}$ unit change with $\mathrm{HR}=$ 1.05(95\% CI, 0.99-1.12) (Beelen et al. 2013).

Several recent studies have shown a significant relationship between long-term exposure to $\mathrm{PM}_{2.5}$ and mortality (Cesaroni et al. 2013; Chen et al. 2013; Elliott et al. 2007; Lepeule et al. 2012; Pelucchi et al. 2009). Our results are quite consistent with these findings, since we found a borderline significant relationship between baseline exposure to $\mathrm{PM}_{2.5}$ and non-accidental mortality.

Cesaroni et al. showed that an increase of $10 \mu \mathrm{g} / \mathrm{m}^{3}$ of $\mathrm{NO}_{2}$ was associated with increase in allcause deaths $\mathrm{HR}=1.03(95 \% \mathrm{CI}, 1.02-1.03)$ in a cohort composed of more than a million participants (Cesaroni et al. 2013). Our results are in line with these findings, as a rising of 19.3 $\mu \mathrm{g} / \mathrm{m}^{3}$ in $\mathrm{NO}_{2}$ was associated with an increase in non-accidental mortality $\mathrm{HR}=1.14(95 \% \mathrm{CI}$, $0.99-1.31)$

In PAARC French study, Filleul et al. showed a borderline significant association between baseline long-term exposure to $\mathrm{SO}_{2}$ and non-accidental mortality (Filleul et al. 2005). These results are in line with our findings.

A recent cohort study in Toronto investigated associations between long-term exposure to ambient volatile organic compounds (VOCs) and mortality. The study population was composed of 58,760 participants followed-up from 1982 to 2004 . That study found that an increase in the IQR of baseline exposure to benzene $\left(0.13 \mu \mathrm{g} / \mathrm{m}^{3}\right)$ was associated with an increase in cancer mortality $\mathrm{HR}=1.06(95 \% \mathrm{CI}, 1.02-1.11 \%)$ (Villeneuve et al. 2013). Our results are concordant with this finding, since we found a significant relationship between an increase by $1.67 \mu \mathrm{g} / \mathrm{m}^{3}$ of baseline exposure to benzene and non-accidental mortality $\mathrm{HR}=1.10$ (95\% CI, 1.01-1.22. 
Previous cohort studies have reported statistically significant, positive associations with cardiovascular (Chen et al. 2013; Lepeule et al. 2012) and respiratory-related mortality (Lipsett et al. 2011; Naess et al. 2007). Our findings provided non-significant results for the relationship between air pollutants and these two specific causes of death. This could be partly due to the relatively few number of deaths from cardiovascular $(\mathrm{N}=165)$ and respiratory $(\mathrm{N}=284)$ diseases recorded in our study, in turn leading to a lack of statistical power. Unfortunately, data on causespecific mortality were not available after 2010 to extend analyses to 2013. Our study has limitations. Retrospective assessment of exposure was performed using the CHIMERE model. Final data contained uncertainties due to the low number of monitoring stations (measurements) in the initial years of the study, especially for $\mathrm{PM}_{2.5}$ and benzene. This resulted in an underestimation of exposure, in particular for these two pollutants (Bentayeb et al. 2014). Moreover, our exposure assessment did not consider traffic emissions which may have led to an underestimation of concentrations in urban areas. However, our exposure model took into account traffic characteristics such as annual average daily traffic, percentage of heavy transport and road distances, in addition to monitored background air pollution, meteorological data, industrial and other sector emissions, as well as dispersion conditions and atmospheric chemistry (Bentayeb et al. 2014).

Another limitation of our study is that we were not able to take into account indoor air pollution as no data were available. We did not take into account occupational exposure which may confound the observed associations between air pollution exposure and mortality. However, it is not likely that this could have a meaningful effect regarding internal cohort comparisons since we adjusted on occupational category taking thus into account the fact that occupational exposure occurs mainly among low grade workers. Additionally the fact that we did not found a significant association between air pollution and respiratory and cardiovascular causes of 
death does not suggest that there could be a substantial confounding effect from occupational exposure, as they are the main diseases induced by airborne exposure.

Moreover, outdoor air quality is characterized by pollution mixture; accordingly, it is difficult to conclude which air contaminant had a specific and independent adverse effect on mortality. The GAZEL cohort participants are not representative of the general population as only individuals with job security were included, although findings of this study could be extrapolated to a subset of comparable population characteristics. Moreover certain categories of the population were excluded (e.g. agricultural workers, self-employed, foreigners). Moreover, we had a small number of events (cause specific mortality) among participants to detect effects (insufficient statistical power).

Our study focused on residential exposure because this was the information available at the time we initiated this study. Because workers spend a large part of their time at work, assessing the work place exposure is definitely an analysis that should have been done. However, our exposure data were measured at zip code scale which not allows distinguishing between workplace and residential exposure. Concentrations were strongly correlated $(\mathrm{R}=1)$.

Another limitation is that our analyses were adjusted on baseline confounders. The large number of missing values does not enable us to adjust models on time-varying covariates (Figure 4). However, sensitivity analyses showed similar results between models adjusted or not on time-dependent confounders (Table 6). No relationship was observed between exposure to air pollution and non-accidental mortality in both models. This is probably due to a lack of statistical power when considering a small number of observations.

Moreover, Gazel is not a representative sample of the French population, thus some caution must be taken regarding the generalizability of our findings. First, it is an occupational cohort and it might happen that participants could have been exposed to certain specific occupational exposures. However previous studies about the population of the company showed that while 
the global mortality rates are lower than for the total French population due to a strong healthy worker effect, the profile of mortality is very similar suggesting that the distribution of health determinants does not differ much between both populations (Chevalier et al. 1987; Poncet et al. 2003).

Second, subjects of the Gazel cohort participated on a voluntary basis which implies selection effects, and indeed it was shown that they were in a better state of health than non-participants (Goldberg et al. 2001). It thus might be that the effects of air pollution we observed in this cohort are in fact to a certain extend underestimated.

Despite its limitations, our study has several strengths. The response rate was particularly high, with most participants responding every year and with very few withdrawals, which is remarkable in a cohort given it the long follow-up. The study is based on a large sample size and takes into account a number of important socioeconomic, demographic, lifestyle and contextual factors.

Participants were geographically distributed in all regions of metropolitan France (excluding Corsica) which ensured measurement of large contrasts in exposure. Moreover, several indicators of exposure were considered: fixed exposure as (1) annual mean exposure at baseline (1989) (2) annual mean exposure one year before death or censure and time dependent exposures as (3) yearly mean exposure during the follow-up before death or censure and (4) average cumulative exposure before death or censure. Effect estimates were generally similar regardless of the methods used to consider exposure. The increases in risk of non-accidental mortality were most associated with baseline concentration of air pollutants compared with other lags of exposure. Finally, all analyses took into account residential history, which was available every year.

Except for $\mathrm{O}_{3}$, stratification by length of follow up showed that associations between nonaccidental mortality and baseline exposure to $\mathrm{PM}, \mathrm{NO}_{2}, \mathrm{SO}_{2}$ and benzene were decreased over 
time. It could be explained by their elevated concentration levels in the first period (1989-1994) and their decreasing over time. However, increasing associations between $\mathrm{O}_{3}$ and mortality, particularly in the last period (2007-2013), could be explained by its high correlation with temperature. This will be investigated in future work.

Results from bi-pollutant models adjusted for individual and contextual covariates did not differ from the uni-pollutant models, which supports the assumption that the effects of each pollutant were independent. These findings are in agreement with previous results (Beelen et al. 2013).

\section{Conclusion}

We investigated the association between long-term exposure to various air pollutants and mortality from non-accidental, cardiovascular and respiratory causes. Our results confirm previous findings of adverse effects of long-term exposure to air pollution, including fine particles, nitrogen dioxide, sulfur dioxide and benzene, on non-accidental mortality. The associations showed here strengthen the evidence that long term exposure to outdoor air pollution is a significant environmental risk factor for mortality. Depending on statistical power, future analyses on this cohort will be conducted on long term effects of air pollution on morbidities, particularly on cardiopulmonary diseases, diabetes, and cognitive functions.

However, due to the limited sample size and the nature of our study (occupational), further investigations are needed in France with a larger representative population sample.

\section{Acknowledgements}

This paper is dedicated to the memory of Christophe Declercq, former coordinator of the surveillance program on air pollution and health at the French Institute for Public Health Surveillance (InVS).

Acknowledgements: The authors express their thanks to EDF-GDF, especially to the Service Général de Médecine de Contrôle, and to the "Caisse centrale d'action sociale du personnel des industries électrique et gazière". We also wish to acknowledge the Population-based Cohort 
Unit, UMS 011 INSERM Versailles St-Quentin University, - responsible for the GAZEL data base management. The GAZEL Cohort Study was funded by EDF-GDF and INSERM, and received grants from the 'Cohortes Santé TGIR Program', Agence nationale de la recherché (ANR) and Agence française de sécurité sanitaire de l'environnement et du travail (AFSSET).The authors would like to thank French air quality monitoring agencies (AASQA) who provided air pollution data. Our thanks also to Jude Sweeney for the English revision of this manuscript.

\section{Conflicts of interest}

None. 
Reference List

Beelen R, Hoek G, van den Brandt PA, Goldbohm RA, Fischer P, Schouten LJ, et al. 2008. Long-term effects of traffic-related air pollution on mortality in a Dutch cohort (NLCSAIR study). Environ Health Perspect 116: 196-202.

Beelen R, Raaschou-Nielsen O, Stafoggia M, Andersen ZJ, Weinmayr G, Hoffmann B, et al. 2013. Effects of long-term exposure to air pollution on natural-cause mortality: an analysis of 22 European cohorts within the multicentre ESCAPE project. Lancet 383: 785-795.

Bentayeb M, Helmer C, Raherison C, Dartigues JF, Tessier JF, Annesi-Maesano I. 2010. Bronchitis-like symptoms and proximity air pollution in French elderly. Respir Med 104: 880-888.

Bentayeb M, Stempfelet M, Wagner M, Zins M, Bonenfant S, Songeur C, et al. 2014. Retrospective modeling outdoor air pollution at a fine spatial scale in France, 19892008. Atmos Environ 92: 267-279.

Cesaroni G, Badaloni C, Gariazzo C, Stafoggia M, Sozzi R, Davoli M, et al. 2013. Long-term exposure to urban air pollution and mortality in a cohort of more than a million adults in Rome. Environ Health Perspect 121: 324-331.

Chen H, Goldberg MS, Burnett RT, Jerrett M, Wheeler AJ, Villeneuve PJ. 2013. Long-term exposure to traffic-related air pollution and cardiovascular mortality. Epidemiology 24: $35-43$.

Chevalier A, Leclerc A, Blanc C, Goldberg M. 1987. Disparités sociales et professionnelles de la mortalité des travailleurs d'Électricité et Gaz de France. Population 6: 863-880.

Crouse DL, Peters PA, van DA, Goldberg MS, Villeneuve PJ, Brion O, et al. 2012. Risk of nonaccidental and cardiovascular mortality in relation to long-term exposure to low concentrations of fine particulate matter: a Canadian national-level cohort study. Environ Health Perspect 120: 708-714.

Elliott P, Shaddick G, Wakefield JC, de HC, Briggs DJ. 2007. Long-term associations of outdoor air pollution with mortality in Great Britain. Thorax 62: 1088-1094.

Filleul L, Rondeau V, Vandentorren S, Le MN, Cantagrel A, nnesi-Maesano I, et al. 2005. Twenty five year mortality and air pollution: results from the French PAARC survey. Occup Environ Med 62: 453-460.

Goldberg M, Chastang JF, Leclerc A, Zins M, Bonenfant S, Bugel I, et al. 2001. Socioeconomic, demographic, occupational, and health factors associated with participation in a long-term epidemiologic survey: a prospective study of the French GAZEL cohort and its target population. Am J Epidemiol 154: 373-384.

Goldberg M, Leclerc A, Bonenfant S, Chastang JF, Schmaus A, Kaniewski N, et al. 2007. Cohort profile: the GAZEL Cohort Study. Int J Epidemiol 36: 32-39.

Hart JE, Garshick E, Dockery DW, Smith TJ, Ryan L, Laden F. 2011. Long-term ambient multipollutant exposures and mortality. Am J Respir Crit Care Med 183: 73-78. 
Hoek G, Krishnan RM, Beelen R, Peters A, Ostro B, Brunekreef B, et al. 2013. Long-term air pollution exposure and cardio- respiratory mortality: a review. Environ Health 12: 43.

Lepeule J, Laden F, Dockery D, Schwartz J. 2012. Chronic exposure to fine particles and mortality: an extended follow-up of the Harvard Six Cities study from 1974 to 2009. Environ Health Perspect 120: 965-970.

Lipsett MJ, Ostro BD, Reynolds P, Goldberg D, Hertz A, Jerrett M, et al. 2011. Long-term exposure to air pollution and cardiorespiratory disease in the California teachers study cohort. Am J Respir Crit Care Med 184: 828-835.

Menut L, Goussebaile A, Bessagnet B, Khvorostiyanov D, Ung A. 2012. Impact of realistic hourly emissions profiles on air pollutants concentrations modelled with CHIMERE. Atmospheric Environment 49: 233-244.

Naess O, Nafstad P, Aamodt G, Claussen B, Rosland P. 2007. Relation between concentration of air pollution and cause-specific mortality: four-year exposures to nitrogen dioxide and particulate matter pollutants in 470 neighborhoods in Oslo, Norway. Am J Epidemiol 165: 435-443.

Pavillon G, Maguin P. 1993. [The 10th revision of the International Classification of Diseases]. Rev Epidemiol Sante Publique 41: 253-255.

Pelucchi C, Negri E, Gallus S, Boffetta P, Tramacere I, La VC. 2009. Long-term particulate matter exposure and mortality: a review of European epidemiological studies. BMC Public Health 9: 453.

Poncet M, Chevalier A, Bumsel F, Lahon G. 2003. [Mortality among active workers at EDGGDF: social and occupational disparities and evolution]. Rev Epidemiol Sante Publique 51: 481-491.

Puett RC, Hart JE, Yanosky JD, Paciorek C, Schwartz J, Suh H, et al. 2009. Chronic fine and coarse particulate exposure, mortality, and coronary heart disease in the Nurses' Health Study. Environ Health Perspect 117: 1697-1701.

Townsend P, Phillimore P, Beattie A. 1988. Health and deprivation: inequality and the North. Bristol: Croom Helm.

Villeneuve PJ, Jerrett M, Su J, Burnett RT, Chen H, Brook J, et al. 2013. A cohort study of intra-urban variations in volatile organic compounds and mortality, Toronto, Canada. Environ Pollut 183: 30-39.

Zou B, Wilson JG, Zhan FB, Zeng Y. 2009. Air pollution exposure assessment methods utilized in epidemiological studies. J Environ Monit 11: 475-490. 


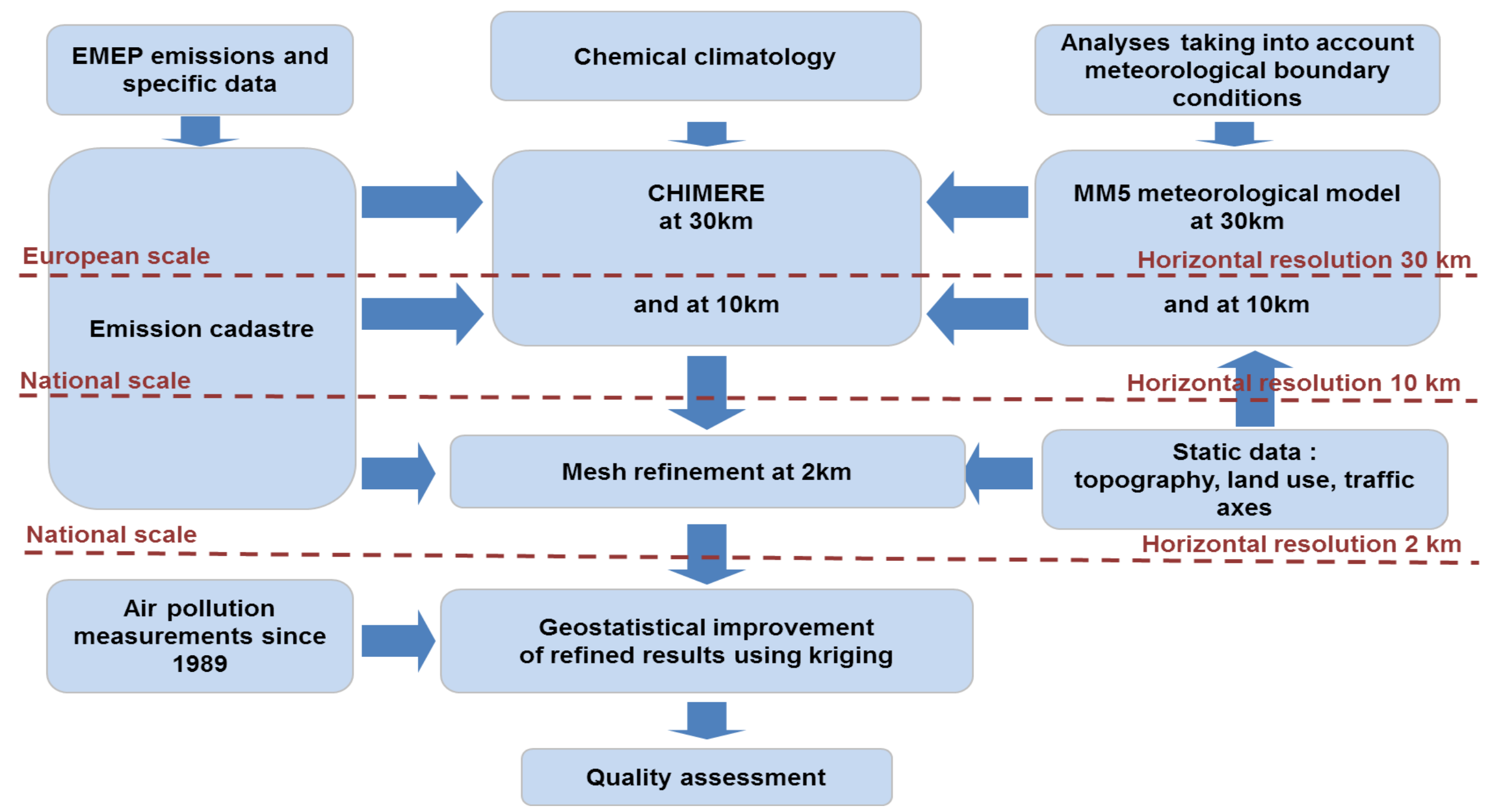

Figure 1 Diagram of the modelling strategy 


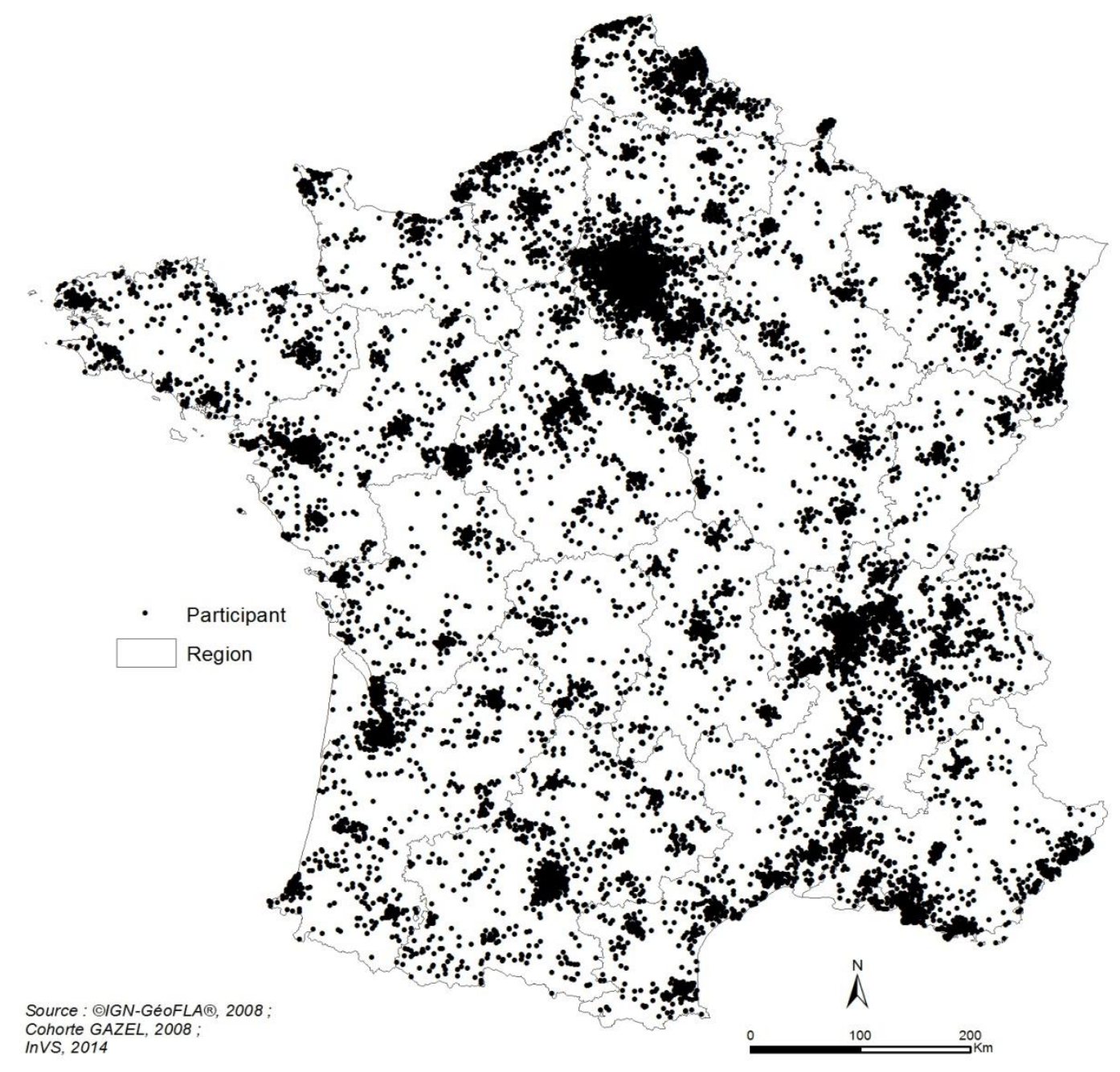

Figure 2 Geographical distribution of the Gazel cohort participants according to their residential zip codes. 


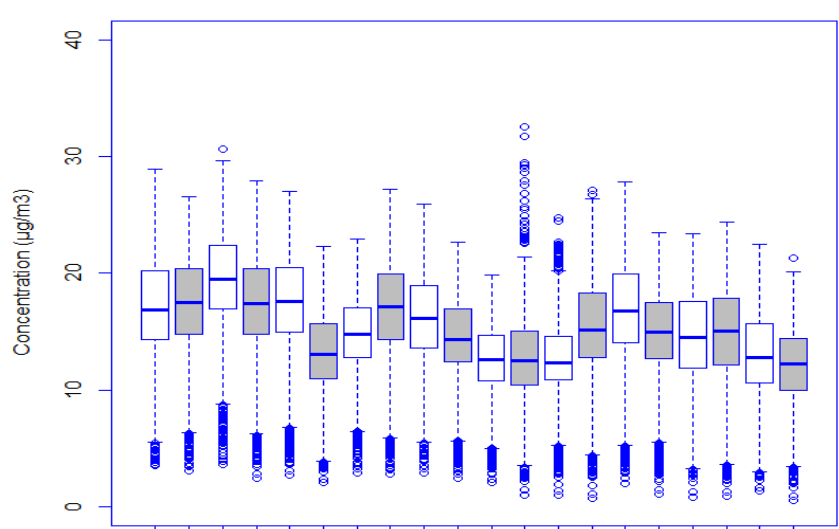

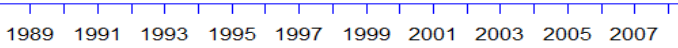
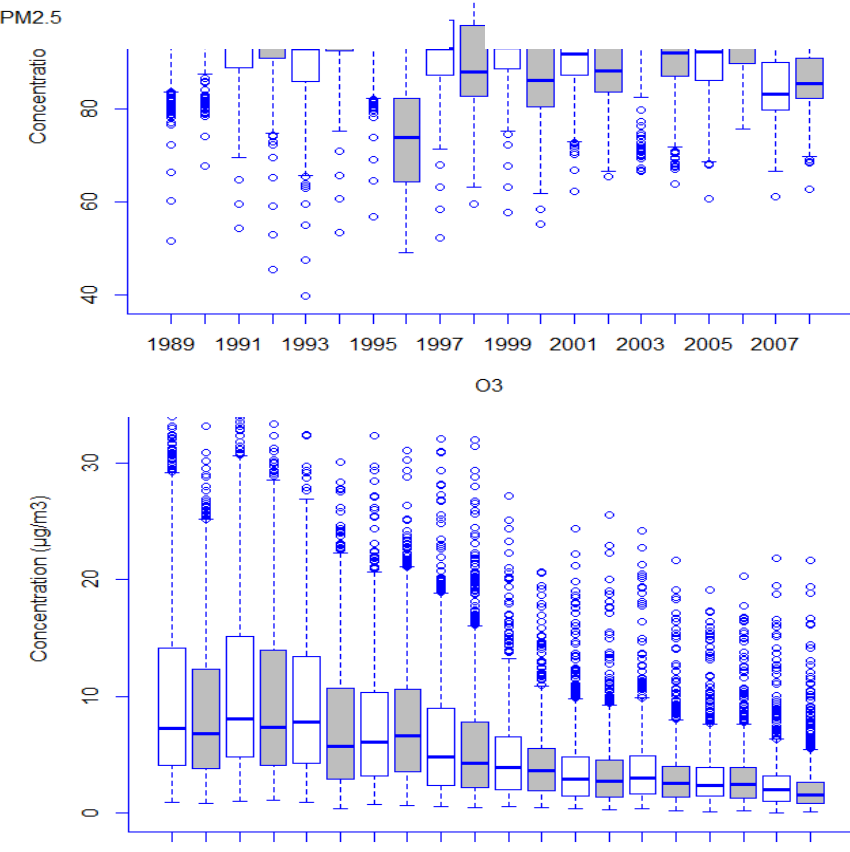

$\begin{array}{lllllllllll}1989 & 1991 & 1993 & 1995 & 1997 & 1999 & 2001 & 2003 & 2005 & 2007\end{array}$

$\mathrm{sO} 2$

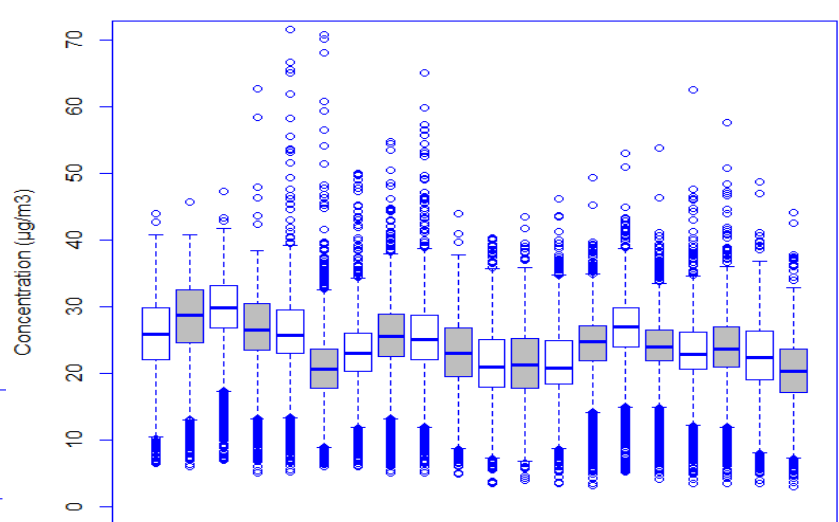

PM10

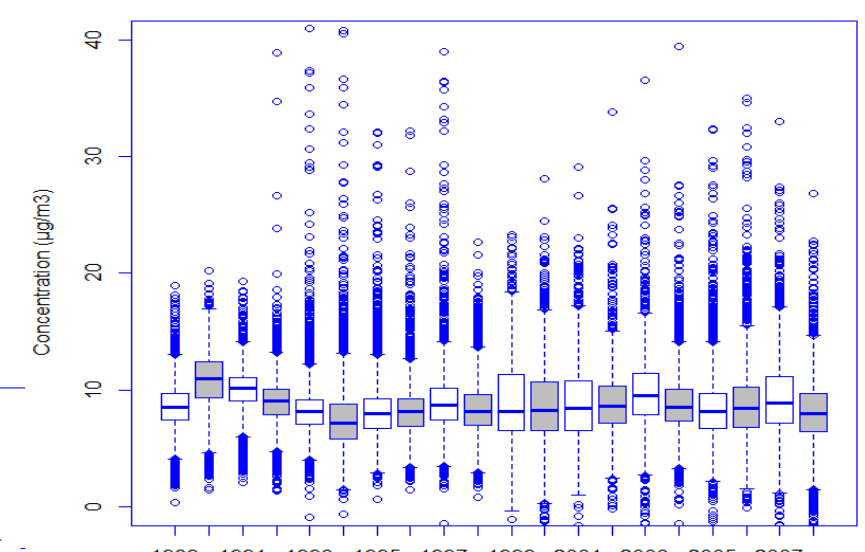

$\begin{array}{llllllllllll}1989 & 1991 & 1993 & 1995 & 1997 & 1999 & 2001 & 2003 & 2005 & 2007\end{array}$ PM10-2.5
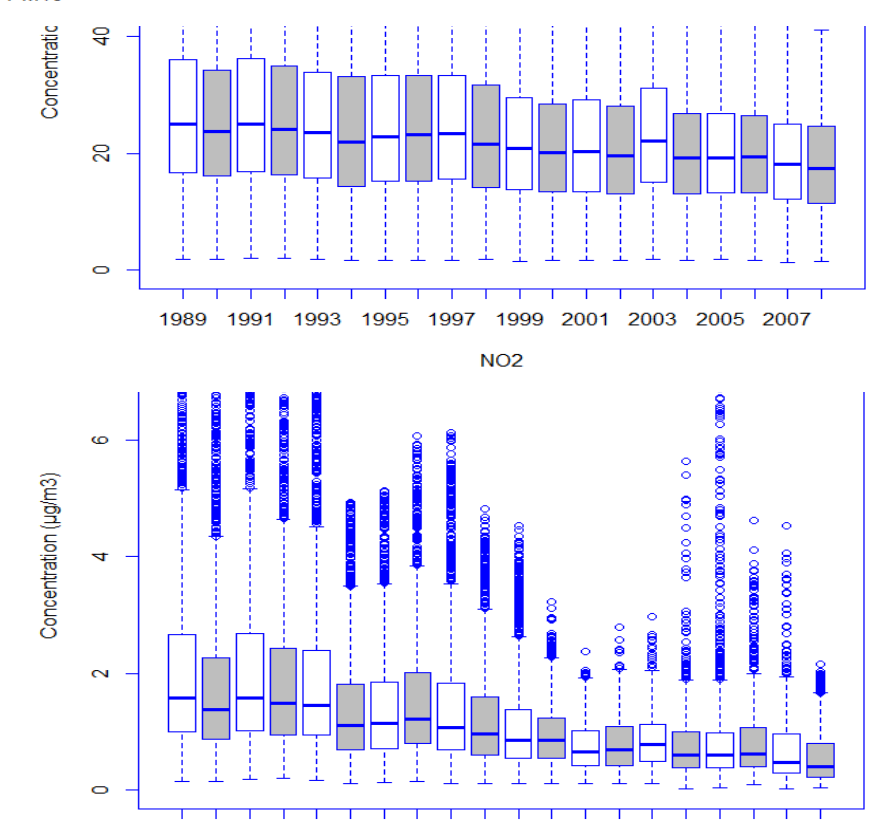

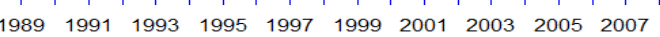

Benzene

Figure 3 Distribution of air pollutants among Gazel cohort study participants. Air pollution levels (in $\mu \mathrm{g} / \mathrm{m} 3$ ) from 1989 to 2008 . Box plots (fifth percentile, first quartile, median, third quartile, ninety-fifth percentile). PM10,PM2.5, suspended particulates of aerodynamic diameter less than 2.5 and 10 microns; NO2, nitrogen dioxide; O3, ozone; $\mathrm{SO} 2$, sulfur dioxide; $\mathrm{C} 6 \mathrm{H} 6$, benzene. 
Body mass index

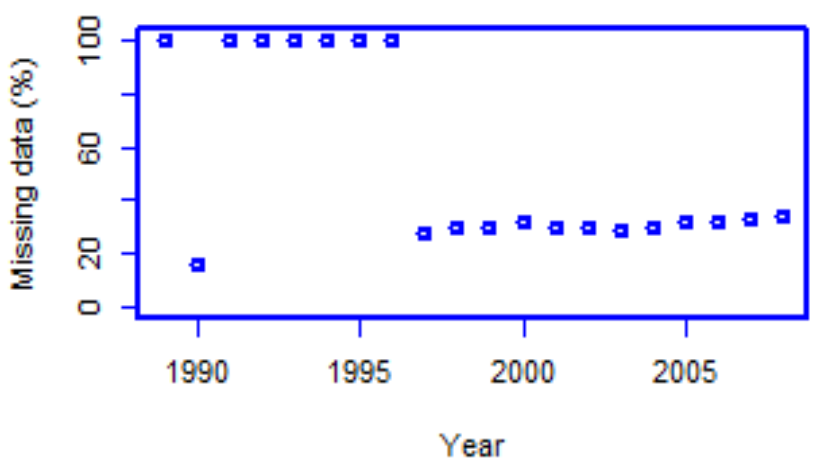

Highest level of education

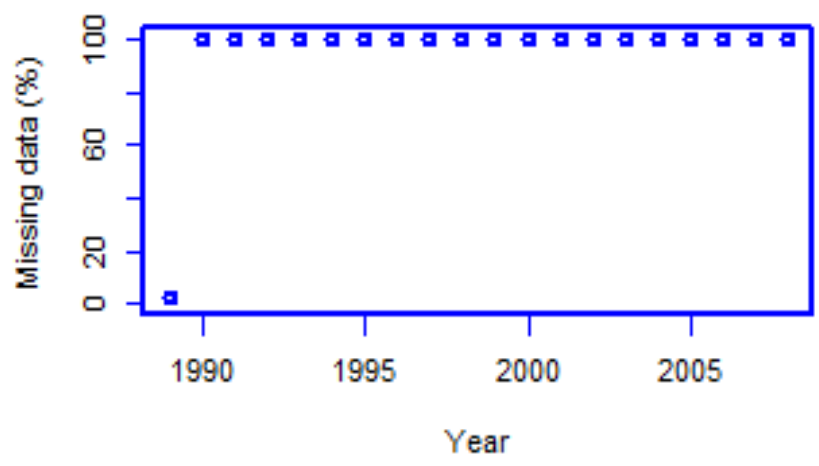

Smoking status

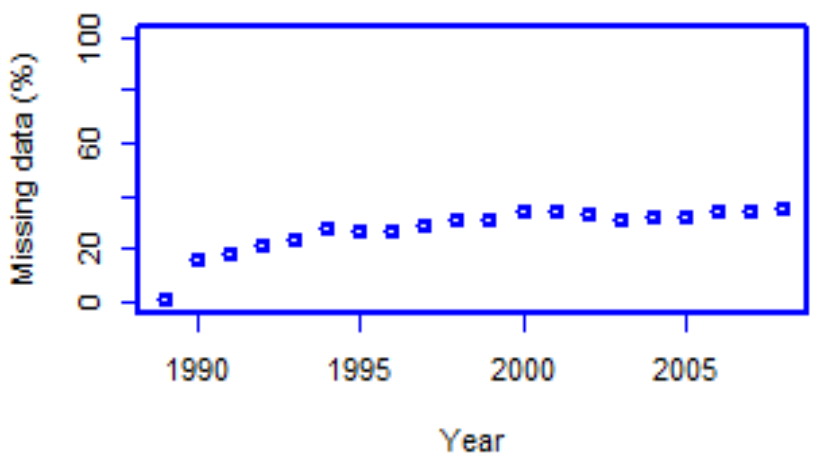

Martial status

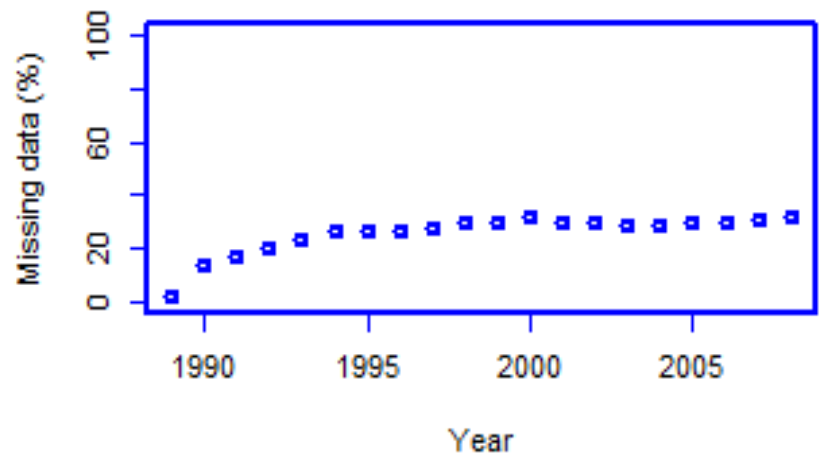

Occupational level

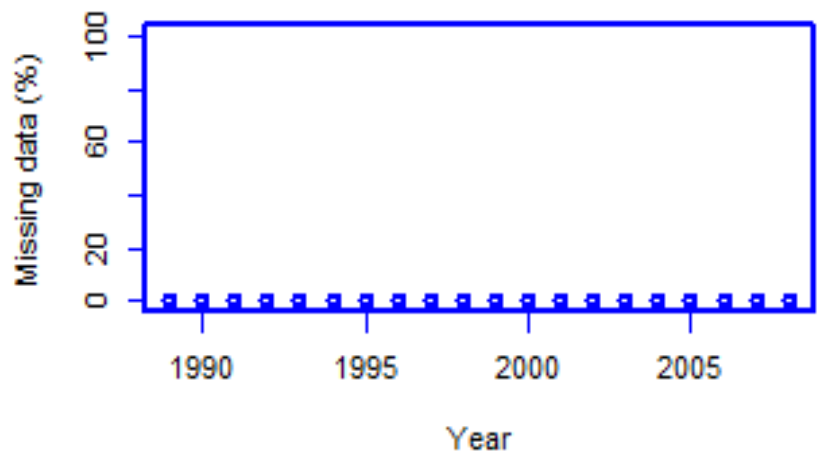

Alcohol consumption

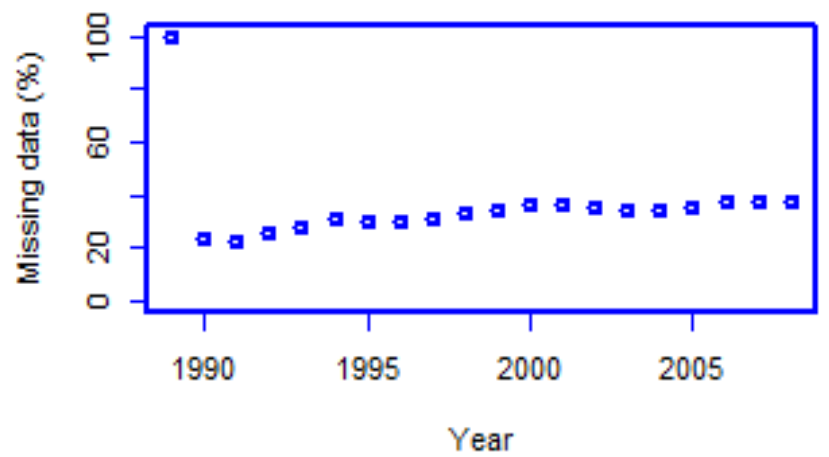

Figure 4 Missing values of individual characteristics from 1989 to 2008 
Table 1. Baseline characteristics of participants and air pollutant concentrations ${ }^{*}$ at their residences across levels of confounders.

\begin{tabular}{|c|c|c|c|c|c|c|c|c|}
\hline $\mathrm{N}=20,327$ & $\begin{array}{c}\text { Mean } \pm \text { sd } \\
\text { or } \mathrm{N}(\%)\end{array}$ & $\mathrm{PM}_{10}$ & $\begin{array}{c}\mathrm{PM}_{10-} \\
2.5 \\
\end{array}$ & $\mathrm{PM}_{2.5}$ & $\mathrm{NO}_{2}$ & $\mathrm{O}_{3}$ & $\mathrm{SO}_{2}$ & Benzene \\
\hline Age (years) & $43.7 \pm 3.5$ & & & & & & & \\
\hline BMI & $24.5 \pm 3.2$ & & & & & & & \\
\hline \multicolumn{9}{|l|}{ Sex } \\
\hline Males & $\begin{array}{l}14,790 \\
(72.8)\end{array}$ & 25.2 & 8.4 & 16.8 & 26.5 & 101.9 & 9.2 & 2 \\
\hline Females & $5,537(27.2)$ & 26.8 & 8.6 & 18.2 & 32.3 & 100.3 & 11.6 & 2.8 \\
\hline \multicolumn{9}{|l|}{ Martial status } \\
\hline Single & $753(3.7)$ & 27.2 & 8.6 & 18.5 & 34.6 & 98.8 & 13.0 & 3.2 \\
\hline $\begin{array}{r}\text { Divorced/separated or } \\
\text { widowed }\end{array}$ & $1,242(6.1)$ & 26.8 & 8.7 & 18.2 & 32 & 100.5 & 11.7 & 2.7 \\
\hline Married/cohabiting & $\begin{array}{l}18,331 \\
(90.2)\end{array}$ & 25.5 & 8.4 & 17.1 & 27.5 & 101.6 & 9.6 & 2.2 \\
\hline \multicolumn{9}{|l|}{$\begin{array}{r}\text { Highest level of } \\
\text { education }\end{array}$} \\
\hline Low & $1,378(6.8)$ & 25.8 & 8.5 & 17.3 & 28.5 & 101.1 & 10 & 2.3 \\
\hline Intermediate & $\begin{array}{l}13,680 \\
(67.3)\end{array}$ & 25.3 & 8.4 & 16.8 & 26.7 & 101.8 & 9.2 & 2.1 \\
\hline High & $4,804(23.6)$ & 26.7 & 8.5 & 18.1 & 31.9 & 100.7 & 11.7 & 2.7 \\
\hline \multicolumn{9}{|l|}{ Occupational level } \\
\hline Low & $3,748(18.4)$ & 24.7 & 8.4 & 16.2 & 24.2 & 102.1 & 8.1 & 1.8 \\
\hline Intermediate & $\begin{array}{l}11,677 \\
(57.4)\end{array}$ & 25.6 & 8.5 & 17.1 & 27.7 & 101.7 & 9.7 & 2.2 \\
\hline High & $4,902(24.2)$ & 26.6 & 8.4 & 18.2 & 31.8 & 100.3 & 11.8 & 2.7 \\
\hline \multicolumn{9}{|l|}{ Smoking status } \\
\hline Never & $8,718(42.9)$ & 25.9 & 8.5 & 17.4 & 28.8 & 101.3 & 10.1 & 2.3 \\
\hline Former & $5,836(28.7)$ & 25.3 & 8.4 & 16.9 & 27.0 & 101.7 & 9.4 & 2.1 \\
\hline Current & $5,618(27.6)$ & 25.6 & 8.4 & 17.2 & 28.1 & 101.4 & 10 & 2.2 \\
\hline \multicolumn{9}{|l|}{ Alcohol consumption } \\
\hline Abstinent & $530(2.6)$ & 25.9 & 8.5 & 17.3 & 28.7 & 100.8 & 10.4 & 2.3 \\
\hline Low & $\begin{array}{l}14,249 \\
(70.1)\end{array}$ & 25.9 & 8.5 & 17.4 & 28.7 & 101.5 & 10.1 & 2 \\
\hline Medium & $3,174(15.6)$ & 24.9 & 8.3 & 16.6 & 26.1 & 101.6 & 9 & 2 \\
\hline High & $1,953(9.6)$ & 25.1 & 8.3 & 16.8 & 26.2 & 101.5 & 9 & 2 \\
\hline \multicolumn{9}{|l|}{ Mortality $^{\dagger}$} \\
\hline Non-accidental & $1,967(9.7)$ & 25.8 & 8.6 & 17.2 & 27.8 & 101.2 & 9.9 & 2.2 \\
\hline Cardiovascular & $165(0.8)$ & 25.6 & 8.6 & 17.0 & 25.4 & 101.5 & 8.6 & 1.9 \\
\hline Respiratory & $284(1.4)$ & 27.3 & 9.3 & 18.0 & 30.0 & 101.3 & 11.1 & 2.2 \\
\hline \multicolumn{9}{|l|}{ Legth of follow-up } \\
\hline 1989-1994 & $20,136(99)$ & 25,4 & 8,2 & 17,1 & 27,1 & 101,2 & 9,7 & 2,2 \\
\hline $1995-2000$ & $\begin{array}{l}19,968 \\
(98.2)\end{array}$ & 25,7 & 8,6 & 17,2 & 28,0 & 101,2 & 10,2 & 2,2 \\
\hline $2001-2006$ & $\begin{array}{l}19,809 \\
(97.4)\end{array}$ & 26,0 & 8,7 & 17,3 & 28,0 & 100,9 & 9,9 & 2,3 \\
\hline
\end{tabular}


$\begin{array}{ccc}2007-2013 & \begin{array}{c}19,428 \\ (95.6)\end{array} \quad 25,9\end{array}$

$8,6 \quad 17,3 \quad 27,8 \quad 101,3 \quad 9,8$

2,2

${ }^{*}$ Annual mean concentrations at baseline (1989)

†Non-accidental mortality measured from 1989 to 2013, cardiovascular and respiratory death from 1989 to 2010.

BMI, body mass index. 
Table 2. Descriptive statistics of air pollution concentrations according to time lags exposure* and Pearson correlation coefficients in 2008.

\begin{tabular}{|c|c|c|c|c|c|c|c|c|c|c|c|c|c|c|c|c|c|c|c|}
\hline \multirow[b]{2}{*}{$\begin{array}{c}\text { Pollutant } \\
\left(\mu \mathrm{g} / \mathrm{m}^{3}\right)\end{array}$} & \multicolumn{3}{|c|}{$\begin{array}{c}\text { annual mean exposure at } \\
\text { baseline (1989) }\end{array}$} & \multicolumn{3}{|c|}{$\begin{array}{l}\text { annual mean exposure } \\
\text { one year before the event }\end{array}$} & \multicolumn{3}{|c|}{$\begin{array}{c}\text { yearly mean exposure } \\
\text { before the event }\end{array}$} & \multicolumn{3}{|c|}{$\begin{array}{l}\text { average cumulative } \\
\text { exposure before the } \\
\text { event }\end{array}$} & \multicolumn{7}{|c|}{ Pearson correlation coefficient in 2008} \\
\hline & $\begin{array}{c}\text { Mean } \pm \\
\text { SD }\end{array}$ & Median & IQR & $\begin{array}{c}\text { Mean } \pm \\
\text { SD }\end{array}$ & Median & $\mathrm{IQR}$ & $\begin{array}{c}\text { Mean } \pm \\
\text { SD }\end{array}$ & Median & IQR & $\begin{array}{c}\text { Mean } \pm \\
\text { SD }\end{array}$ & Median & IQR & $\mathrm{PM}_{10}$ & $\mathrm{PM}_{2.5}$ & $\begin{array}{c}\mathrm{PM}_{10-} \\
2.5 \\
\end{array}$ & $\mathrm{NO}_{2}$ & $\mathrm{O}_{3}$ & $\mathrm{SO}_{2}$ & Benzene \\
\hline $\mathrm{PM}_{10}$ & $25 \pm 5.5$ & 25.8 & 7.8 & $24 \pm 5.7$ & 24.3 & 7.4 & $24 \pm 5.7$ & 24.1 & 7.5 & $25 \pm 5.1$ & 25.4 & 6.7 & 1.00 & 0.77 & 0.78 & 0.72 & -0.21 & 0.57 & 0.59 \\
\hline $\mathrm{PM}_{2.5}$ & $17 \pm 4.3$ & 16.8 & 5.9 & $15 \pm 4.3$ & 15.3 & 5.9 & $15 \pm 4.3$ & 15.1 & 5.9 & $16 \pm 3.9$ & 16.3 & 5.4 & & 1.00 & 0.20 & 0.77 & -0.38 & 0.58 & 0.66 \\
\hline $\mathrm{PM}_{10-2.5}$ & $8 \pm 2.2$ & 8.5 & 2.2 & $9 \pm 3.1$ & 8.6 & 3.3 & $9 \pm 3.1$ & 8.6 & 3.3 & $9 \pm 2.1$ & 8.9 & 2.2 & & & 1.00 & 0.34 & 0.06 & 0.30 & 0.25 \\
\hline $\mathrm{NO}_{2}$ & $28 \pm 14.6$ & 25 & 19.3 & $24 \pm 12.2$ & 21.7 & 16.6 & $23 \pm 12.1$ & 21.4 & 16.5 & $26 \pm 13.1$ & 23.3 & 17.9 & & & & 1.00 & -0.34 & 0.56 & 0.88 \\
\hline $\mathrm{O}_{3}$ & $101 \pm 8.5$ & 101.7 & 9 & $94 \pm 11.7$ & 93.9 & 15.4 & $94 \pm 11.6$ & 93.5 & 15.5 & $97 \pm 9.6$ & 96.1 & 12.3 & & & & & 1.00 & -0.13 & -0.44 \\
\hline $\mathrm{SO}_{2}$ & $9 \pm 7.6$ & 7.2 & 10.1 & $6 \pm 5.4$ & 4.1 & 5.5 & $6 \pm 5.4$ & 3.9 & 5.3 & $8 \pm 5.9$ & 6.2 & 7.7 & & & & & & 1.00 & 0.41 \\
\hline $\mathrm{C}_{6} \mathrm{H}_{6}$ & $2 \pm 1.8$ & 1.6 & 1.7 & $1 \pm 1.3$ & 0.97 & 1 & $1 \pm 1.2$ & 0.94 & 1 & $2 \pm 1.4$ & 1.8 & 1.3 & & & & & & & 1.00 \\
\hline
\end{tabular}

* Exposure was defined as: fixed exposure (1) annual mean exposure at baseline (1989) (2) annual mean exposure one year before death or censure and time dependent exposures as (3) yearly mean exposure during the follow-up before death or censure and (4) average cumulative exposure before death or censure.

$\mathrm{PM}_{10}, \mathrm{PM}_{2.5}$, suspended particles of aerodynamic diameter less than 10 and $2.5 \mathrm{~mm}$, respectively; $\mathrm{PM}_{10-2.5}, \mathrm{PM}_{10}$ minus $\mathrm{PM}_{2.5} ; \mathrm{NO}_{2}$, nitrogen dioxide; $\mathrm{O}_{3}, \mathrm{Ozone}_{2}$ $\mathrm{SO}_{2}$, sulfur dioxide. 
Table 3. Adjusted $\mathrm{HR}^{\mathrm{a}}$ and $95 \%$ CIs for all-cause and cause-specific mortality ${ }^{\mathrm{b}}$ associated with an interquartile change in air pollutants exposure ${ }^{c}$

\begin{tabular}{|c|c|c|c|c|}
\hline $\begin{array}{r}\text { Annual mean exposure at } \\
\text { baseline (1989) }\end{array}$ & $\begin{array}{c}\text { IQR } \\
\left(\mu \mathrm{g} / \mathrm{m}^{3}\right)\end{array}$ & $\begin{array}{l}\text { Non-accidental } \\
\text { HR }(95 \% \text { CI })\end{array}$ & $\begin{array}{l}\text { Cardiovascular } \\
\text { HR }(95 \% \mathrm{CI})\end{array}$ & $\begin{array}{c}\text { Respiratory } \\
\text { HR }(95 \% \text { CI) }\end{array}$ \\
\hline $\mathrm{PM}_{10}$ & 7.8 & $1.14(1.05,1.25)^{*}$ & $1.21(0.89,1.63)$ & $1.06(0.83,1.34)$ \\
\hline $\mathrm{PM}_{10-2,5}$ & 2.2 & $1.09(1.04,1.15)^{*}$ & $1.13(0.95,1.33)$ & $1.11(0.98,1.27)$ \\
\hline $\mathrm{PM}_{2,5}$ & 5.9 & $1.09(0.99,1.20)^{\dagger}$ & $1.12(0.82,1.52)$ & $0.93(0.72,1.20)$ \\
\hline $\mathrm{NO}_{2}$ & 19.3 & $1.14(0.99,1.31)^{\dagger}$ & $0.99(0.59,1.64)$ & $0.91(0.63,1.32)$ \\
\hline $\mathrm{O}_{3}$ & 9 & $0.98(0.91,1.06)$ & $0.95(0.72,1.25)$ & $1.01(0.83,1.23)$ \\
\hline $\mathrm{SO}_{2}$ & 10.1 & $1.08(0.98,1.20)$ & $0.88(0.61,1.26)$ & $0.89(0.68,1.17)$ \\
\hline Benzene & 1.7 & $1.10(1.00,1.22)^{*}$ & $1.05(0.73,1.51)$ & $0.92(0.72,1.19)$ \\
\hline $\begin{array}{r}\text { Annual mean exposure } \\
\text { one year before event }\end{array}$ & $\begin{array}{c}\text { IQR } \\
\left(\mu \mathrm{g} / \mathrm{m}^{3}\right)\end{array}$ & $\begin{array}{l}\text { Non-accidental } \\
\text { HR }(95 \% \mathrm{CI})\end{array}$ & $\begin{array}{l}\text { Cardiovascular } \\
\text { HR }(95 \% \mathrm{CI})\end{array}$ & $\begin{array}{l}\text { Respiratory } \\
\text { HR }(95 \% \text { CI) }\end{array}$ \\
\hline $\mathrm{PM}_{10}$ & 7.4 & $1.07(0.96,1.20)$ & $1.05(0.78,1.42)$ & $1.04(0.81,1.34)$ \\
\hline $\mathrm{PM}_{10-2,5}$ & 3.3 & $1.04(0.98,1.11)^{\dagger}$ & $1.01(0.84,1.21)$ & $1.05(0.92,1.21)$ \\
\hline $\mathrm{PM}_{2,5}$ & 5.9 & $1.08(0.94,1.24)$ & $1.08(0.73,1.61)$ & $0.94(0.68,1.31)$ \\
\hline $\mathrm{NO}_{2}$ & 16.6 & $1.08(0.90,1.29)$ & $0.86(0.49,1.49)$ & $0.75(0.49,1.17)$ \\
\hline $\mathrm{O}_{3}$ & 15.4 & $0.84(0.71,1.00)$ & $0.83(0.49,1.42)$ & $0.91(0.61,1.36)$ \\
\hline $\mathrm{SO}_{2}$ & 5.5 & $1.09(0.99,1.20)^{\dagger}$ & $0.80(0.58,1.12)$ & $0.90(0.68,1.18)$ \\
\hline Benzene & 1 & $1.01(0.93,1.10)$ & $0.75(0.54,1.04)$ & $0.98(0.79,1.21)$ \\
\hline $\begin{array}{r}\text { yearly mean exposure } \\
\text { before event }\end{array}$ & $\begin{array}{c}\text { IQR } \\
\left(\mu \mathrm{g} / \mathrm{m}^{3}\right)\end{array}$ & $\begin{array}{l}\text { Non-accidental } \\
\text { HR }(95 \% \text { CI })\end{array}$ & $\begin{array}{l}\text { Cardiovascular } \\
\text { HR }(95 \% \mathrm{CI})\end{array}$ & $\begin{array}{l}\text { Respiratory } \\
\text { HR }(95 \% \text { CI) }\end{array}$ \\
\hline $\mathrm{PM}_{10}$ & 7.5 & $1.12(1.01,1.24)^{*}$ & $1.02(0.75,1.39)$ & $1.14(0.89,1.45)$ \\
\hline $\mathrm{PM}_{10-2,5}$ & 3.3 & $1.06(1.00,1.12) *$ & $0.97(0.80,1.16)$ & $1.12(0.98,1.27)$ \\
\hline $\mathrm{PM}_{2,5}$ & 5.9 & $1.09(0.95,1.26)$ & $1.12(0.76,1.66)$ & $0.92(0.67,1.28)$ \\
\hline $\mathrm{NO}_{2}$ & 16.5 & $1.08(0.90,1.29)$ & $0.88(0.51,1.54)$ & $0.76(0.48,1.18)$ \\
\hline $\mathrm{O}_{3}$ & 15.5 & $0.82(0.69,1,01)$ & $0.93(0.54,1.59)$ & $0.84(0.55,1.28)$ \\
\hline $\mathrm{SO}_{2}$ & 5.3 & $1.10(1.00,1.21)^{*}$ & $0.84(0.61,1.17)$ & $0.91(0.69,1.21)$ \\
\hline Benzene & 1 & $1.00(0.92,1.10)$ & $0.78(0.56,1.08)$ & $1.03(0.83,1.29)$ \\
\hline $\begin{array}{l}\text { Average cumulative } \\
\text { exposure before event }\end{array}$ & $\begin{array}{c}\text { IQR } \\
\left(\mu \mathrm{g} / \mathrm{m}^{3}\right)\end{array}$ & $\begin{array}{l}\text { Non-accidental } \\
\text { HR }(95 \% \text { CI })\end{array}$ & $\begin{array}{l}\text { Cardiovascular } \\
\text { HR }(95 \% \mathrm{CI})\end{array}$ & $\begin{array}{l}\text { Respiratory } \\
\text { HR }(95 \% \text { CI) }\end{array}$ \\
\hline $\mathrm{PM}_{10}$ & 6.7 & $1.11(1.00,1.23)^{*}$ & $1.11(0.82,1.51)$ & $1.00(0.77,1.28)$ \\
\hline $\mathrm{PM}_{10-2,5}$ & 2.2 & $1.09(1.02,1.16)^{*}$ & $1.04(0.87,1.26)$ & $1.06(0.91,1.23)$ \\
\hline $\mathrm{PM}_{2,5}$ & 5.4 & $1.07(0.94,1.22)$ & $1.16(0.80,1.67)$ & $0.90(0.66,1.23)$ \\
\hline $\mathrm{NO}_{2}$ & 17.9 & $1.13(0.94,1.36)$ & $1.00(0.56,1.77)$ & $0.80(0.51,1.24)$ \\
\hline $\mathrm{O}_{3}$ & 12.3 & $0.88(0.76,1.02)$ & $0.89(0.56,1.41)$ & $0.97(0.69,1.38)$ \\
\hline $\mathrm{SO}_{2}$ & 7.7 & $1.13(0.99,1.28)^{\dagger}$ & $0.91(0.62,1.35)$ & $0.85(0.61,1.18)$ \\
\hline Benzene & 1.3 & $1.06(0.94,1.20)$ & $0.93(0.62,1.38)$ & $0.95(0.70,1.30)$ \\
\hline
\end{tabular}

$* \mathrm{p}<0.05, \dagger \mathrm{p}<0.10$

${ }^{a}$ All models were adjusted for baseline individual covariates : age, gender, body mass index (BMI), Marital status, education, occupational level, smoking status, alcohol intake, region of residence and for contextual factors (1999) : Townsend deprivation index, the percentage of households not liable for tax, the average temperature, the principal road network and the population density.

${ }^{\mathbf{b}}$ At baseline, analyses were performed from 1989 to 2013. All time-dependent analyses were performed from 1989 to 2008 .

${ }^{\mathbf{c}}$ Exposure was defined as: fixed exposure (1) annual mean exposure at baseline (1989) (2) annual mean exposure one year before death or censure and time dependent exposures as (3) yearly mean exposure during the follow-up before death or censure and (4) average cumulative exposure before death or censure. $\mathrm{PM}_{10}, \mathrm{PM}_{2.5}$, suspended particles of aerodynamic diameter less than 10 and $2.5 \mathrm{~mm}$, respectively; $\mathrm{PM}_{10}$ ${ }_{2.5}, \mathrm{PM}_{10}$ minus $\mathrm{PM}_{2.5} ; \mathrm{NO}_{2}$, nitrogen dioxide; $\mathrm{O}_{3}$, Ozone; $\mathrm{SO}_{2}$, sulfur dioxide. 
Table 4. HRs ${ }^{\mathbf{a}}$ for non-accidental mortality associated with an interquartile-range (IQR) change in air pollutants exposure ${ }^{\mathbf{b}}$, stratified by length of follow-up.

\begin{tabular}{|c|c|c|c|c|c|c|c|c|}
\hline Periods & $\begin{array}{c}\text { Non- } \\
\text { accidental } \\
\text { mortality (N) }\end{array}$ & $\mathbf{P M}_{10}$ & $\mathbf{P M}_{10-2.5}$ & $\mathbf{P M}_{2.5}$ & $\mathrm{NO}_{2}$ & $\mathrm{O}_{3}$ & $\mathrm{SO}_{2}$ & Benzene \\
\hline 1989-1994 & 191 & $1.20(1.17-1.22)^{*}$ & $1.13(1.11-1.15)^{*}$ & $1.10(1.07-1.12)^{*}$ & $1.10(1.07-1.13)^{*}$ & $1.01(0.99-1.02)$ & $1.04(1.02-1.07)^{*}$ & $1.09(1.07-1.11)^{*}$ \\
\hline $1995-2000$ & 359 & $1.11(1.09-1.14)^{*}$ & $1.08(1.07-1.10)^{*}$ & $1.04(1.01-1.06)^{*}$ & $1.06(1.03-1.09) *$ & $1.06(1.04-1.08)^{*}$ & $1.00(0.97-1.02)$ & $1.08(1.06-1.10)^{*}$ \\
\hline 2001-2006 & 518 & $1.15(1.12-1.18)^{*}$ & $1.12(1.10-1.13)^{*}$ & $1.06(1.03-1.08)^{*}$ & $1.03(1.00-1.06)^{*}$ & $1.11(1.09-1.13)^{*}$ & $0.97(0.95-1.00)$ & $1.05(1.02-1.07)^{*}$ \\
\hline $2007-2013$ & 899 & $1.02(0.99-1.06)$ & $1.03(1.01-1.06)^{*}$ & $0.97(0.94-1.00)$ & $0.96(0.93-1.00)$ & $1.20(1.17-1.23)^{*}$ & $0.91(0.88-0.93)^{*}$ & $1.00(0.97-1.02)$ \\
\hline
\end{tabular}

"p $<0.05$, all interactions between periods of follow-up and air pollutants are statistically significant $(\mathrm{p}<0.001)$.

a All models were adjusted for baseline individual covariates : age, gender, body mass index (BMI), Marital status, education, occupational level, smoking status, alcohol intake and for contextual factors (1999) : Townsend deprivation index, the percentage of nontaxable households, the average temperature, the principal road network and the population density.

${ }^{b}$ Annual mean exposure at baseline (1989) in a follow-up from 1989 to 2013. IQR: PM10 $=7.8 \mu \mathrm{g} / \mathrm{m}^{3}, \mathrm{PM} 10-2.5=2.2 \mu \mathrm{g} / \mathrm{m}^{3}, \mathrm{PM} .5=5.9 \mu \mathrm{g} / \mathrm{m}^{3}, \mathrm{NO}{ }_{2}$ $=19.3 \mu \mathrm{g} / \mathrm{m}^{3}, \mathrm{O}_{3}=9 \mu \mathrm{g} / \mathrm{m}^{3}, \mathrm{SO}_{2}=10.1 \mu \mathrm{g} / \mathrm{m}^{3}$, benzene $=1.7 \mu \mathrm{g} / \mathrm{m}^{3}$.

$\mathrm{PM}_{10}, \mathrm{PM}_{2.5}$, suspended particles of aerodynamic diameter less than 10 and $2.5 \mathrm{~mm}$, respectively; $\mathrm{PM}_{10-2.5}, \mathrm{PM}_{10}$ minus $\mathrm{PM}_{2.5} ; \mathrm{NO}_{2}$, nitrogen dioxide; $\mathrm{O}_{3}$, Ozone; $\mathrm{SO}_{2}$, sulfur dioxide. 
Table 5. Adjusted ${ }^{\mathrm{a}} \mathrm{HR}$ and $95 \%$ CIs for all-cause mortality ${ }^{\mathrm{b}}$ associated with an interquartile change in air pollutants exposure ${ }^{\mathrm{c}}$ in bi- pollutant models

\begin{tabular}{llc}
\hline $\mathbf{P M}_{2.5}$ & Main pollutant & Pollutant adjusted for \\
\hline Adjusted for $\mathrm{O}_{3}$ & $1.08(0.98,1.19)$ & $0.98(0.91,1.06)$ \\
\hline Ajusted for benzene & $1.04(0.94,1.17)$ & $1.08(0.96,1.20)$ \\
\hline PM $_{10}$ & $1.14(1.02,1.27)^{*}$ & $1.00(0.89,1.13)$ \\
\hline Adjusted for $\mathrm{SO}_{2}$ & $1.12(1.02,1.24)^{*}$ & $1.05(0.95,1.17)$ \\
Ajusted for benzene & & \\
\hline PM $10-2.5$ & $1.08(1.02,1.14)^{*}$ & $1.03(0.93,1.15)$ \\
\hline Adjusted for $\mathrm{PM}_{2.5}$ & $1.09(1.04,1.15)^{*}$ & $0.98(0.91,1.05)$ \\
Adjusted for $\mathrm{O}_{3}$ & & $1.08(1.03,1.14)^{*}$ \\
\hline Benzene & $1.09(0.99,1.20)^{+}$ & $0.98(0.91,1.06)$ \\
\hline Adjusted for $\mathrm{PM}_{10-2.5}$ & $1.10(1.00,1.21)^{*}$ &
\end{tabular}

$* \mathrm{p}<0.05 ; \dagger \mathrm{p}<0.10$

${ }^{a}$ All models were adjusted for baseline individual covariates : age, sex, body mass index (BMI), Marital status, education, occupational level, smoking status, alcohol intake, region of residence and for the following contextual factors (1999) : Townsend deprivation index, the percentage of households not liable for tax, the average temperature, the principal road network and the population density.

${ }^{\mathrm{b}}$ All-cause mortality from 1989 to 2013.

${ }^{\mathrm{c} A n n u a l ~ m e a n ~ e x p o s u r e ~ a t ~ b a s e l i n e ~(1989) . ~}$

$\mathrm{PM}_{2.5}, \mathrm{PM}_{10}$, suspended particles of aerodynamic diameter less than 2.5 and $10 \mathrm{~mm}$, respectively; $\mathrm{PM}_{10-2.5}, \mathrm{PM}_{10}$ minus $\mathrm{PM}_{2.5} ; \mathrm{NO}_{2}$, nitrogen dioxide; $\mathrm{O}_{3}$, Ozone; $\mathrm{SO}_{2}$, sulfur dioxide. 
Table 6. Adjusted HR and 95\% CIs for non-accidental mortality associated with an interquartile change in air pollutants exposure ${ }^{1}$

\begin{tabular}{rccc}
\hline & $\mathrm{IQR}\left(\mu \mathrm{g} / \mathrm{m}^{3}\right)$ & $\mathrm{HR}(95 \% \mathrm{Cl})^{2}$ & $\mathrm{HR}(95 \% \mathrm{Cl})^{3}$ \\
\hline $\mathrm{PM}_{10}$ & 7.5 & $0.99(0.84,1.17)$ & $0.98(0.77,1.23)$ \\
$\mathrm{PM}_{10-2,5}$ & 3.3 & $1.03(0.93,1.13)$ & $0.97(0.84,1.11)$ \\
$\mathrm{PM}_{2,5}$ & 5.9 & $0.92(0.73,1.14)$ & $1.03(0.76,1.38)$ \\
$\mathrm{NO}_{2}$ & 16.5 & $1.05(0.78,1.40)$ & $1.18(0.79,1.77)$ \\
$\mathrm{O}_{3}$ & 15.5 & $0.79(0.60,1.03)$ & $0.72(0.50,1,05)$ \\
$\mathrm{SO}_{2}$ & 5.3 & $1.00(0.85,1.17)$ & $1.00(0.78,1.26)$ \\
Benzene & 1 & $1.03(0.89,1.18)$ & $1.06(0.88,1.28)$ \\
\hline
\end{tabular}

${ }^{1}$ Exposure was defined as: yearly mean exposure during the follow-up before death or censure.

${ }^{2}$ Models were adjusted for baseline covariates : age, gender, body mass index (BMI), Marital status, education, occupational level, smoking status, alcohol intake, region of residence and for contextual factors (1999) : Townsend deprivation index, the percentage of households not liable for tax, the average temperature, the principal road network and the population density.

${ }^{3}$ Models were adjusted for time varying covariates : age, gender, body mass index (BMI), Marital status, education, occupational level, smoking status, alcohol intake, region of residence and for contextual factors (1999) : Townsend deprivation index, the percentage of households not liable for tax, the average temperature, the principal road network and the population density.

$\mathrm{PM}_{10}, \mathrm{PM}_{2.5}$, suspended particles of aerodynamic diameter less than 10 and $2.5 \mathrm{~mm}$, respectively; $\mathrm{PM}_{10-2.5}$, $\mathrm{PM}_{10}$ minus $\mathrm{PM}_{2.5} ; \mathrm{NO}_{2}$, nitrogen dioxide; $\mathrm{O}_{3}$, Ozone; $\mathrm{SO}_{2}$, sulfur dioxide. 